\title{
Radiological Monitoring of the Treatment of Solid Tumors in Practice
}

\section{Radiologisches Monitoring der Therapie von soliden Tumoren in der Praxis}

Authors

Affiliations
M. K. Ganten ${ }^{1}$, T. M. Ganten ${ }^{2}$, H. P. Schlemmer ${ }^{1}$

Radiology, German Cancer Research Center, Heidelberg

2 Gastroenterology, University Hospital Heidelberg
Key words

- CT

metastases

- staging

received 7.5.2013

accepted $\quad 23.10 .2013$

Bibliography

DOI http://dx.doi.org/

10.1055/s-0033-1356329

Published online: 21.2.2014

Fortschr Röntgenstr 2014; 186: 466-473 @ Georg Thieme

Verlag KG Stuttgart · New York . ISSN 1438-9029

\section{Correspondence}

Dr. Maria-Katharina Ganten

Radiology, German Cancer

Research Center

INF 280

69120 Heidelberg

Tel.: ++49/62 21/418135

Fax: ++49/62 21/32 9254

m.ganten@dkfz.de

\section{Abstract}

Purpose: Thanks to advances in cancer therapy, the diagnosis of "incurable cancer" is increasingly able to be changed to a chronic disease that is manageable over long periods, resulting in a change in the clinical management of cancer patients with solid tumors. New parameters are needed to measure the success of targeted therapy in clinical trials. Materials and Methods: Review article on the basis of selective literature research.

Results: In order to assess how well solid tumors respond to treatment, size-based criteria called RECIST (Response Evaluation Criteria in Solid tumors) have been defined. These criteria have been validated in large oncology trials and are currently used most frequently. New molecular therapies often do not - or at least do not immediately - reduce the size of a tumor. Therefore, RECIST evaluation should be critically assessed especially in the case of modern therapies. Any additional available tumor biology information should be considered. In radiology new methods and developments of RECIST have been introduced to better assess the success of targeted therapy. Conclusion: Assessment according to RECIST has been proven for the follow-up of classic tumor therapy. For the monitoring of targeted therapies, new parameters are often required. Therefore, some specific tumor- and therapy-adapted criteria have already been defined to better evaluate treatment success in clinical trials.

Key points:

- Follow-up evaluation of treatment is becoming increasingly important in modern oncology.

- Conventional cytostatic/cytotoxic treatments can be evaluated on the basis of size according to RECIST.
- However, approx. $80 \%$ of newly approved oncological agents are based on molecular mechanisms of action.

- In the case of molecular treatment forms, the tumor volume does not necessarily correlate with the course of the disease.

- Therefore, there are new practice-relevant treatment-adapted and tumor-adapted imaging methods.

Citation Format:

- Ganten MK, Ganten TM, Schlemmer HP. Radiological Monitoring of the Treatment of Solid Tumors in Practice. Fortschr Röntgenstr 2014; 186: 466-473

\section{Zusammenfassung}

$\nabla$

Hintergrund: Dank der großen Fortschritte in der onkologischen Therapie wird Krebs zunehmend zu einer chronischen über lange Zeiträume beherrschbaren Erkrankung. Hierdurch hat sich das klinische Management für Tumorpatienten mit soliden Tumoren verändert. Neue Parameter sind erforderlich, den Erfolg der zielgerichteten Medikamente sog. „Targeted Therapies“ in klinischen Studien zu messen.

Material und Methoden: Übersichtsarbeit auf der Basis einer selektiven Literaturaufarbeitung.

Ergebnisse: Das Therapieansprechen solider Tumoren wurde bisher anhand der Größenänderung nach RECIST (Response Evaluation Criteria In Solid Tumors) beurteilt. Diese Kriterien wurden in großen onkologischen Studien validiert und werden breit eingesetzt. Für die Verlaufskontrolle der klassischen zytostatisch/zytotoxischen Tumortherapie hat sich die Beurteilung nach RECIST bewährt. Neue molekulare Therapien bewirken jedoch häufig nicht oder nicht sofort - eine Verkleinerung des Tumors. Daher ist die Tumorgröße alleine heute in vielen Fällen nicht mehr ausreichend zur Beurteilung des Therapieeffektes und kann zu Fehleinschätzungen 
führen. Gerade bei modernen Therapien ist die Beurteilung nach RECIST kritisch zu betrachten. Zusätzlich verfügbare Informationen zur Tumorbiologie sollten berücksichtigt werden. In der Radiologie werden zunehmend neue Verfahren und Weiterentwicklungen von RECIST eingeführt, um den Erfolg der „Targeted Therapy“ besser beurteilen zu können. Diese haben in vielen Fällen Praxisreife erlangt und werden hier diskutiert.

Schlussfolgerungen: Für das Monitoring zielgerichteter Therapien sind neue Parameter erforderlich und verfügbar. Schon heute sind spezifische tumor- und therapieangepasste Kriterien für klinische Studien festgelegt, um den Erfolg moderner molekularer Therapieverfahren radiologisch besser beurteilen $\mathrm{zu}$ können.

\section{Background}

$\nabla$

The increase in life expectancy has resulted in an increase in the cancer incidence rate. Statistically speaking, more than half of all cancer patients are still alive five years after being diagnosed [1]. Consequently, early diagnosis and follow-up have become increasingly important. The probability of living a long life with or following a tumor is constantly increasing. Thanks to modern treatments, the once fatal diagnosis of "incurable cancer" has been able to be changed in many cases to a chronic disease that can be successfully managed over long time periods.

Prior to the start of treatment, it is difficult to determine which patients will benefit from a treatment. The evaluation of treatment effectiveness on the basis of the overall survival (OS) requires a large number of patients and long observation periods. Therefore, the criteria for predicting the clinical effectiveness of a treatment targeting molecular objectives are becoming increasingly important. Lab parameters, molecular and genomic analyses and radiological imaging provide information regarding tumor responsiveness.

The cytotoxic effect of standard chemotherapeutic agents generally leads to shrinking of solid tumors in the case of treatment response.

Radiological monitoring of changes in size is the method of choice in this regard.

However, the number of new types of treatment in which treatment success can no longer be determined on the basis of size is steadily increasing. Classic cytotoxic and cytostatic effects are only seen in approx. $20 \%$ of new treatments [2-5]. The increasing use of these modern immunological, antiangiogenic, antihormonal, and antimetabolic treatments requires rethinking of the methods for evaluating effectiveness [6].

The objectification of treatment response with quantifiable parameters must be individually determined in an interdisciplinary manner for the particular patient, for the tumor entity, and for the treatment type. Adapted criteria on the basis of new quantifiable parameters have been developed for several targeted treatments [7-9].

\section{Molecular tumor treatment and radiological diagnostics: \\ $\nabla$}

Targeted therapies use different specific signal paths in tumors as the point of action or affect the formation of blood vessels in the tumor (tumor angiogenesis). This results in different radiological images.

Antiangiogenic treatments in which the VEGF growth factor receptors are blocked inhibit the formation of new blood vessels and therefore result in a reduced blood supply and tumor tissue necrosis. In computed tomography this is seen as a reduced tumor density that is indirectly related to perfusion and cell density (measured in Hounsfield units). This can be accompanied by swelling of the cells and thus by a radiological increase in size [10].

Different forms of tumor cell death occur in the case of direct and indirect cell damage:

In necrosis the cells swell due to an inflow of water. Defects form in the cell membrane, cytoplasm escapes, there is an inflammatory reaction with immigration of granulocytes and other inflammatory cells and an at least temporary increase in the radiologically measured tumor size occurs.

Apoptosis, so-called programmed cell death, is the active form of cell death in an organism. The cells change their morphology in different stages: In the "boiling stage" nucleases dissect the cell nucleus that condenses chromatin. Then in the "blebbing stage" the cell forms blebs and the remains of the cell enveloped by the cell membrane are quickly absorbed by neighboring cells.

In contrast to necrosis, apoptosis is a very quick almost "organized" form of cell death. There is no pronounced inflammatory reaction as in necrosis. However, solid malignant tumors have often lost the ability to undergo apoptosis so that many triggers of programmed cell death are ineffective [10]. Chemotherapy or radiation therapy based on such apoptosis triggers is not successful - a possible reason why a reduction in size as a result of treatment doesn't occur until a relatively late stage $[10-12]$.

\section{Basic principle and limits of RECIST and current modified size criteria \\ 7}

In light of the above information, the underlying principles of the size-based follow-up of tumor treatments require a critical look.

The criteria of the World Health Organization (WHO) used for this purpose [13] are based on a two-dimensional measurement of the tumor lesion diameter. The WHO criteria have already been modified for high-grade malignant cerebral gliomas and defined as the McDonald criteria and were then later further developed as the RANO ( Response Assessment in Neuro-Oncology) criteria [14]. Since the WHO criteria have a high interobserver variability and include relatively imprecise definitions for practical implementation (e.g. regarding minimum tumor size or the selection of representative lesions to be measured), these were largely replaced in 2000 by the simple and more manageable follow-up evaluation according to RECIST (Response Evaluation Criteria In Solid Tumors) [15]. WHO, RECIST (1.0 und 1.1.), Cheson and the RANO criteria were developed for large treatment studies and were therefore 
accepted by the FDA/EMA for new drug approval studies. In 2009 the further developed current version of RECIST 1.1 was published and is still the standard for most clinical studies in systemic solid tumors [16-19]. The goal of the RECIST definition was to allow standardized and simple evaluation of treatment response. Therefore, for example, only the size of a measurable lesion in the longest $1 \mathrm{D} \mathrm{di-}$ ameter is determined and not the surface or the volume, which is even more difficult to determine. In the RECIST evaluation in the initial examination, the radiologist identifies a maximum of five typical target lesions and documents the sum of the longest diameters (lymph nodes are evaluated separately). All other lesions are evaluated as non-target lesions. In the follow-up examinations, the treatment response is classified according to one of four categories [20]:

\section{Target lesion response}

a) Complete response: Disappearance of target and non-target lesions

b) Partial response: With reference to the baseline, reduction of the diameter sum of at least $30 \%$;

c) Progressive disease: With reference to the nadir, increase in the diameter sum of more than $20 \%$ (at least $5 \mathrm{~mm}$ ) or new lesions.

d) Stable disease: With reference to the nadir, diameter range of -30 to $+20 \%$ ( $\bullet$ Fig. 1a).

Assuming a spherically growing tumor, applying the diameter fluctuation to the volume change of the sphere means that the term "stable disease" describes a volume reduction of $65 \%$ to an increase of $73 \%$ ( $\bullet$ Fig. 1b). The RECIST finding therefore only allows basic categorization. This is due to the methodologically based measurement inaccuracy that does not allow clearly defined limits for progression and regression. Computer-aided volume determination is being thoroughly tested, particularly in the lung [21]. However, because it is not successful for all tumors, volumetry has not yet become established in the clinical routine [22]. Follow-up of a solid tumor is therefore usually performed in the clinical routine on the basis of a onedimensional maximum diameter ( $\boldsymbol{O}$ Fig. 2 ). In the case of manual determination of two diameters (as in the WHO criteria) or manual volume determination, the multiplication of measurement inaccuracies in the diameters results in even greater interobserver variability.

Size assessment using response categories results in significant imprecision due to the formalization with percentagebased limits of the response categories, not due to the range for "stable disease". Measurement inaccuracies that can then affect the entire follow-up in the evaluation of the treatment success as a systematic error also occur in the case of varied application in practice.

\section{Evaluation of lymph nodes according to RECIST 1.1}

In the case of largely oval-shaped lymph nodes, the transverse axis instead of the longitudinal axis is evaluated. Lymph nodes with a transverse diameter of at least $15 \mathrm{~mm}$ are evaluated as target lymph nodes, i.e., malignant lymph nodes, while nodes with a short transverse diameter of less than $10 \mathrm{~mm}$ are to be clearly classified as not pathological. A lymph node between $10 \mathrm{~mm}$ and $15 \mathrm{~mm}$ is to be evaluated as a non-target lesion in the baseline examination. When lymph nodes and other target lesions are evaluated together, it must be taken into consideration that the total diameter of all lesions cannot be equal to zero even in the case of a complete response since lymph nodes retain a certain size even in a normal state.

\section{New aspects in the evaluation of clinical response to specific types of treatment \\ $\nabla$}

Due to the increasing problem of insufficient size criteria as explained above, RECIST has been modified to take functional biological information into consideration. FDG-PET (fluoro-deoxy-glucose-positron emission tomography) provides information about the glucose utilization of tumors and can provide additional anatomical information in the combination PET-CT. This method is used among other things for the follow-up of esophageal cancer, intestinal tumors, lymphomas, and melanomas [23]. The so-called PERCIST (PET-Response Criteria in Solid Tumors [24]) were proposed to include biological information obtained with PET particularly in newer molecular treatments during response evaluation. However, these criteria have not yet been further developed since PET is currently only available on a limited basis for practical and economical reasons. An admittedly complex method that takes PET data into consideration and is already used in practice is included in the response categories for lymphomas (Cheson) [25 - 28].

The methods presented in the following ( $\bullet$ Table 1 ) are recommended by the professional associations and are already being increasingly used:

- Advanced-stage hepatocellular carcinoma (HCC) is treated with the multi-tyrosine kinase inhibitor sorafenib. However, HCCs typically do not show a change in size despite treatment response. Large necrotic tumor areas can even result in a measurable increase in size due to tissue swelling. In the SHARP study, the response (tumor response) according to RECIST correlated with an extended survival rate in only $2 \%$ of cases [29]. Contrast-enhanced CT shows the reason for this: Tumor areas with reduced vitality are darker. Solid tumor segments absorb contrast agent. The modification of RECIST (mRECIST) for HCC by the AASLD (American Association for Studies of the Liver Disease) allows for this fact: To determine tumor response in the follow-up period, only the maximum diameter of the still vital perfused tumor tissue in the arterial contrast phase is measured [8].

- In the case of malignant melanoma, the size of the tumor can increase at the start of treatment despite clinical response. During antibody therapy with ipilimumab (CTL antigen-4), a pseudoprogression with an increase in the size of the visible tumor occurs in some patients due to a pronounced immunological reaction and the size only begins to decrease after a period of up to 16 weeks after the start of treatment ( $\bullet$ Fig.3). There is probably an immunostimulation in this case so that an increased number of immune cells migrate into the tumor as shown in $\bullet$ Fig. 4. Only long-term follow-up after the immune reaction subsides shows the decrease in the size of the actual tumor tissue. To determine the type of response in patients who respond to treatment in this way, several "immune-related response criteria" (irRC) 


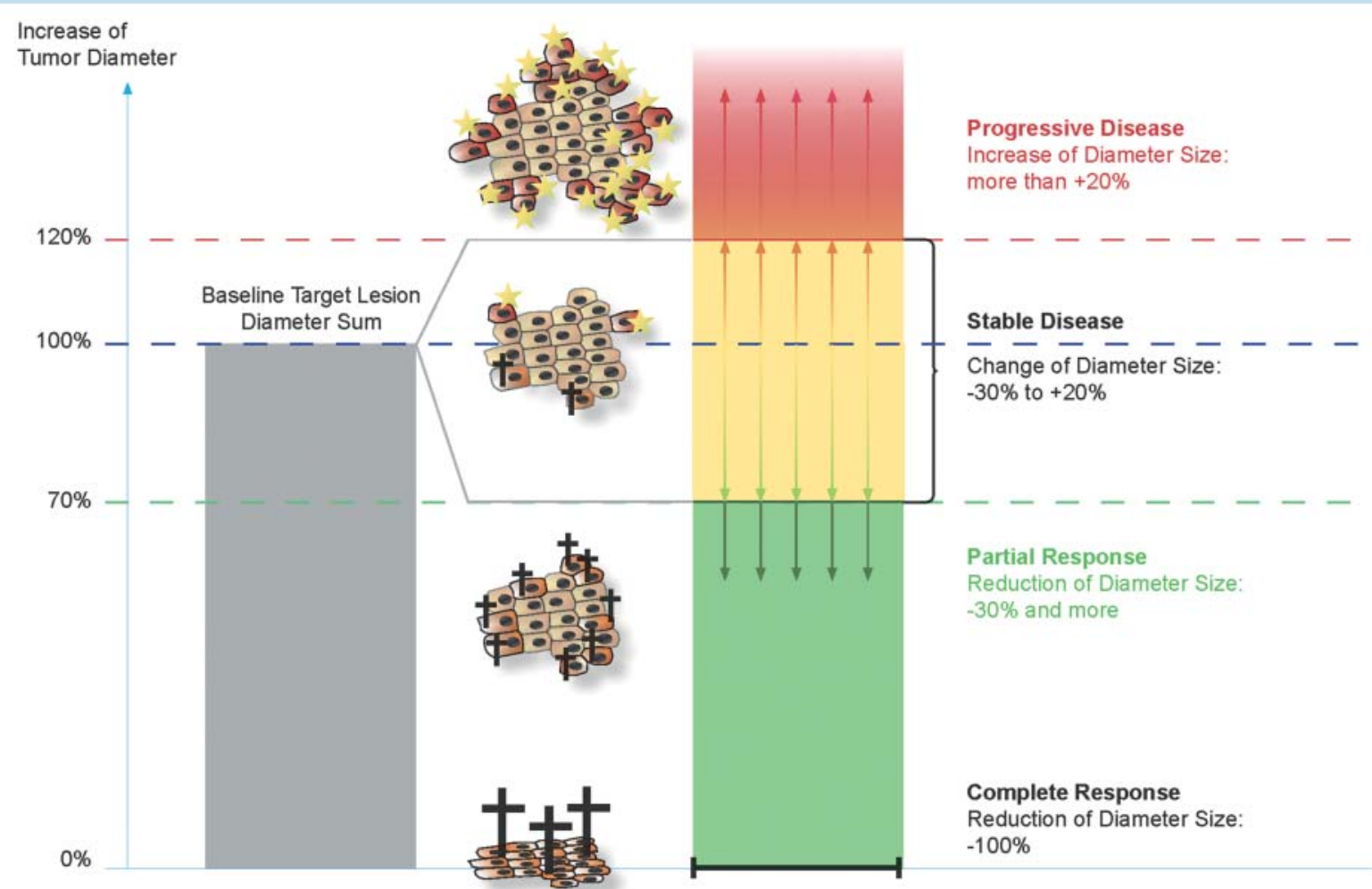

a

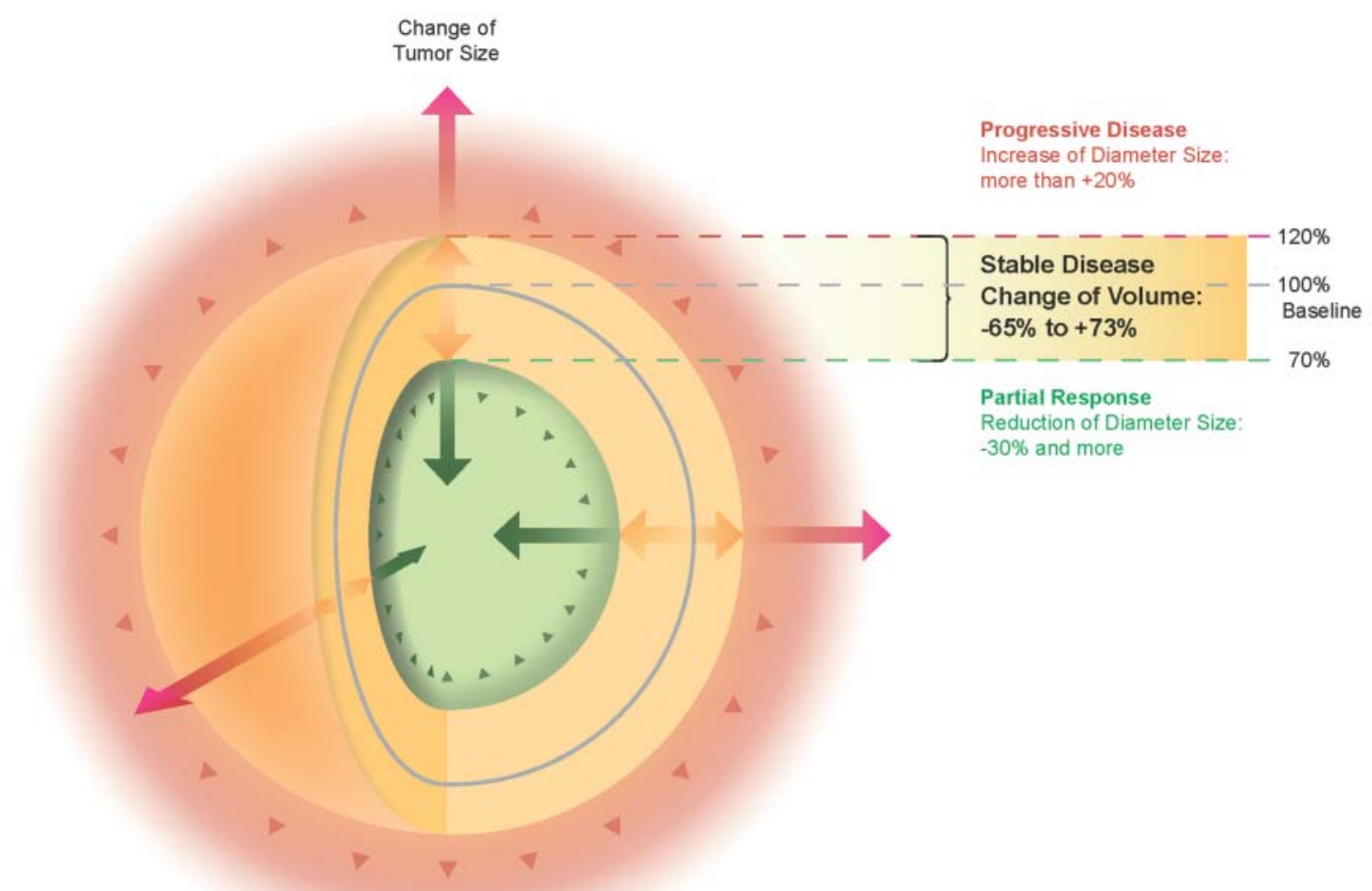

b

Fig. 1 a The four RECIST response categories: The gray bar symbolizes the sum of the diameters of previously defined target lesions. The change in the sum is evaluated during treatment in the follow-up period and is assigned to the response categories according to the percentage change. Accordingly, an increase in the diameter sum of more than $20 \%$ is referred to as progression and a decrease in the tumor diameter sum of more than $30 \%$ is referred to as partial response. b Applying the diameter limits for stable disease to a spherically growing tumor entails a significant volume fluctuation. However, according to the current RECIST criteria, such a substantial fluctuation range is permissible for classifying a disease as stable. 

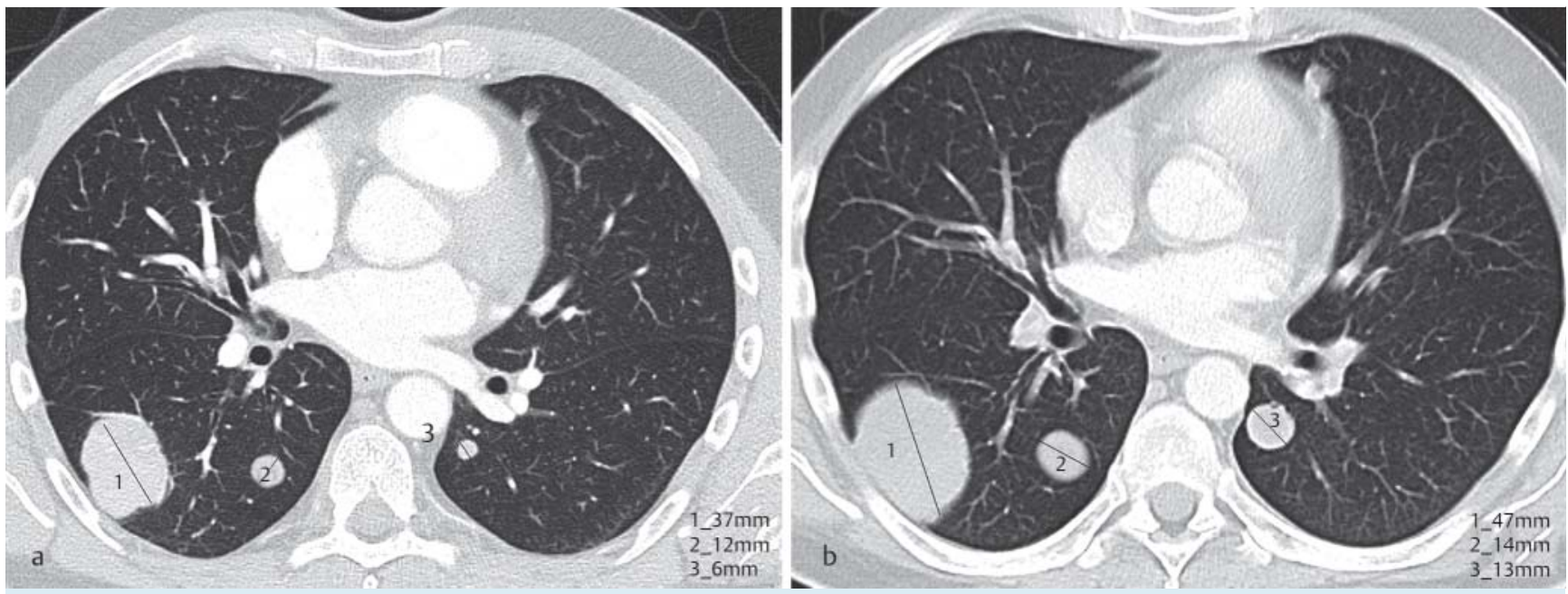

Fig. 2 Example of an increase in size during treatment with cytostatic agents, progressive disease according to RECIST: Lung metastases before treatment a and during treatment $\mathbf{b}$ CT shows a clear increase in the size of the three largest metastases. The change in size indicates a lack of treatment response.

Table 1 Examples of adapted modern criteria for the practical follow-up evaluation of special tumor entities undergoing individualized treatment according to the recommendations of professional associations. The basis of many criteria with the exception of the $\mathrm{CHOI}$ criteria is often still tumor size measurements.

\begin{tabular}{|c|c|c|c|c|}
\hline name of the criteria & tumor & therapeutic agent & basic evaluation principle & imaging modality \\
\hline $\begin{array}{l}\text { mRECIST }[8,36] \\
\text { (AASLD) }\end{array}$ & $\begin{array}{l}\text { HCC } \\
\text { hepatocellular carcinoma }\end{array}$ & $\begin{array}{l}\text { Sorafenib } \\
\text { (tyrosine kinase inhibitor) }\end{array}$ & $\begin{array}{l}\text { the maximum diameter of the still vital perfused tu- } \\
\text { mor tissue measured in the arterial contrast phase }\end{array}$ & $\mathrm{CT} / \mathrm{MRI}$ \\
\hline $\begin{array}{l}\text { irRC [9] } \\
\text { (immune-related } \\
\text { response criteria) }\end{array}$ & $\begin{array}{l}\text { malignant melanoma, } \\
\text { bronchial ca. }\end{array}$ & $\begin{array}{l}\text { Ipilimumab } \\
\text { (CTL antigen-4) }\end{array}$ & $\begin{array}{l}\text { due to the possibility of inflammatory swelling of } \\
\text { tumors after the start of treatment, an increase in } \\
\text { size and newly visible tumors are initially not con- } \\
\text { sidered treatment failure or progressive disease. }\end{array}$ & $\mathrm{CT} / \mathrm{MRI}$ \\
\hline $\begin{array}{l}\text { Choi }[7,27] \\
\text { (author of the criteria) }\end{array}$ & $\begin{array}{l}\text { GIST } \\
\text { gastrointestinal stromal } \\
\text { tumors }\end{array}$ & $\begin{array}{l}\text { Imatinib } \\
\text { (tyrosine kinase inhibitor) }\end{array}$ & consideration of changes in size and density & $\mathrm{CT}$ \\
\hline $\begin{array}{l}\text { Cheson [24] } \\
\text { (author of the criteria) }\end{array}$ & lymphomas & all applied treatments & CT with integration of any available PET information & \\
\hline $\begin{array}{l}\text { Rano [14] } \\
\text { (Response Assessment } \\
\text { in Neuro-Oncology) }\end{array}$ & $\begin{array}{l}\text { high-grade malignant } \\
\text { gliomas }\end{array}$ & all applied treatments & $\begin{array}{l}\text { modified size-based evaluation under consideration } \\
\text { of clinical parameters }\end{array}$ & MRI \\
\hline
\end{tabular}

for the treatment of melanomas with ipilimumab have been defined [9].

- For gastrointestinal stromal tumors (GIST) undergoing tyrosine kinase inhibitor therapy, e.g. with imatinib, the tumor size in the follow-up period is a misleading parameter. Positron emission tomography (PET) with FDG is suitable in this regard for determining early treatment response since the glycometabolism of GIST tumors decreases after only 24 hours in the case of treatment response. Since FDG-PET is only available on a limited basis economically and practically, H. Choi correlated the change in density in contrast-enhanced CT in the portal-venous phase with the response criteria for PET and thus defined relatively easy to use criteria that make it possible to evaluate response primarily on the basis of the change in density in CT. For the practical implementation of diagnostics and follow-up, a group of German experts recently published a consensus recommendation for the "CHOI criteria" since they have found increasing acceptance in practice $[7,30]$.

\section{New methods in radiology for the follow-up evaluation of tumors \\ $\nabla$}

Cellular signal paths that contribute to carcinogenesis allow the development of agents for specific molecular points of action (therapeutic targeting of the hallmarks of cancer [31]). This requires functional imaging that is as coordinated as possible with the particular biological effect (e.g. inhibition of the formation of new blood vessels, trigging of apoptosis, immune system stimulation). However, a single functional parameter is often insufficient to be able to objectively describe tumor behavior. Padhani and colleagues therefore proposed multiparametric imaging for the follow-up of tumors [32, 33]. Therefore, for example, information regarding tumor perfusion obtained from contrastenhanced CT scans can be supplemented by information regarding metabolic activity from FDG-PET. This multiparametric imaging approach is often faced with practical limitations of feasibility not least because of the availability of medical equipment and with regard to cost-effectiveness. For multicenter studies, multiparametric imaging 
Baseline
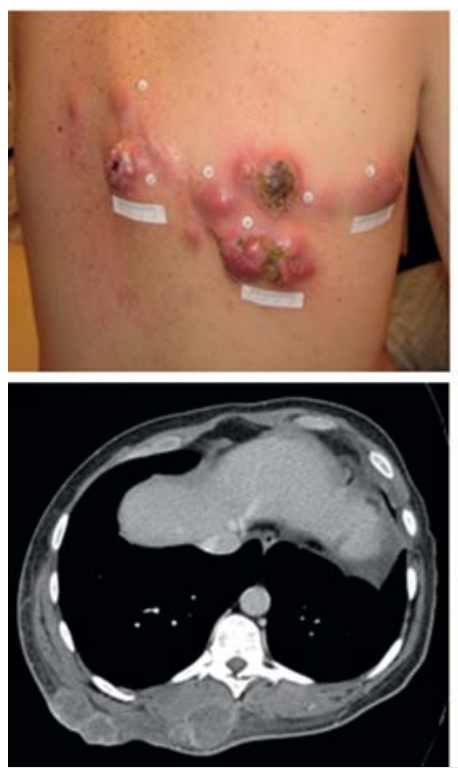

Fig. 3 Example of an advanced malignant melanoma before and during treatment with ipilimumab. A significant increase in the size of the tumor can be seen three months after the start of treatment. However, with continued treatment, a response was seen after 4 months and the patient's
3 Month
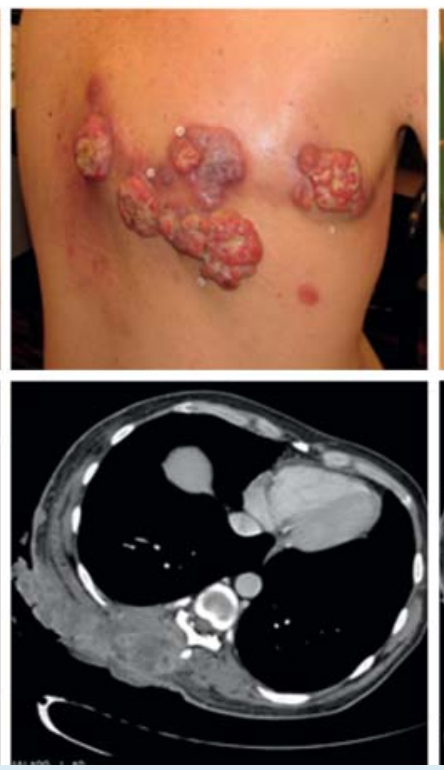

\section{(1)} Vienna

4 Month
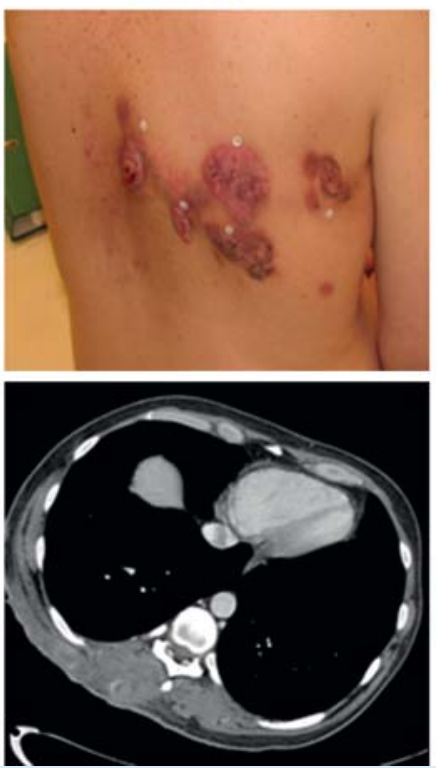

tumor regressed completely in the further follow-up. The patient is still in mission after years. With permission of K. Harmankaya, Dermatology UKL

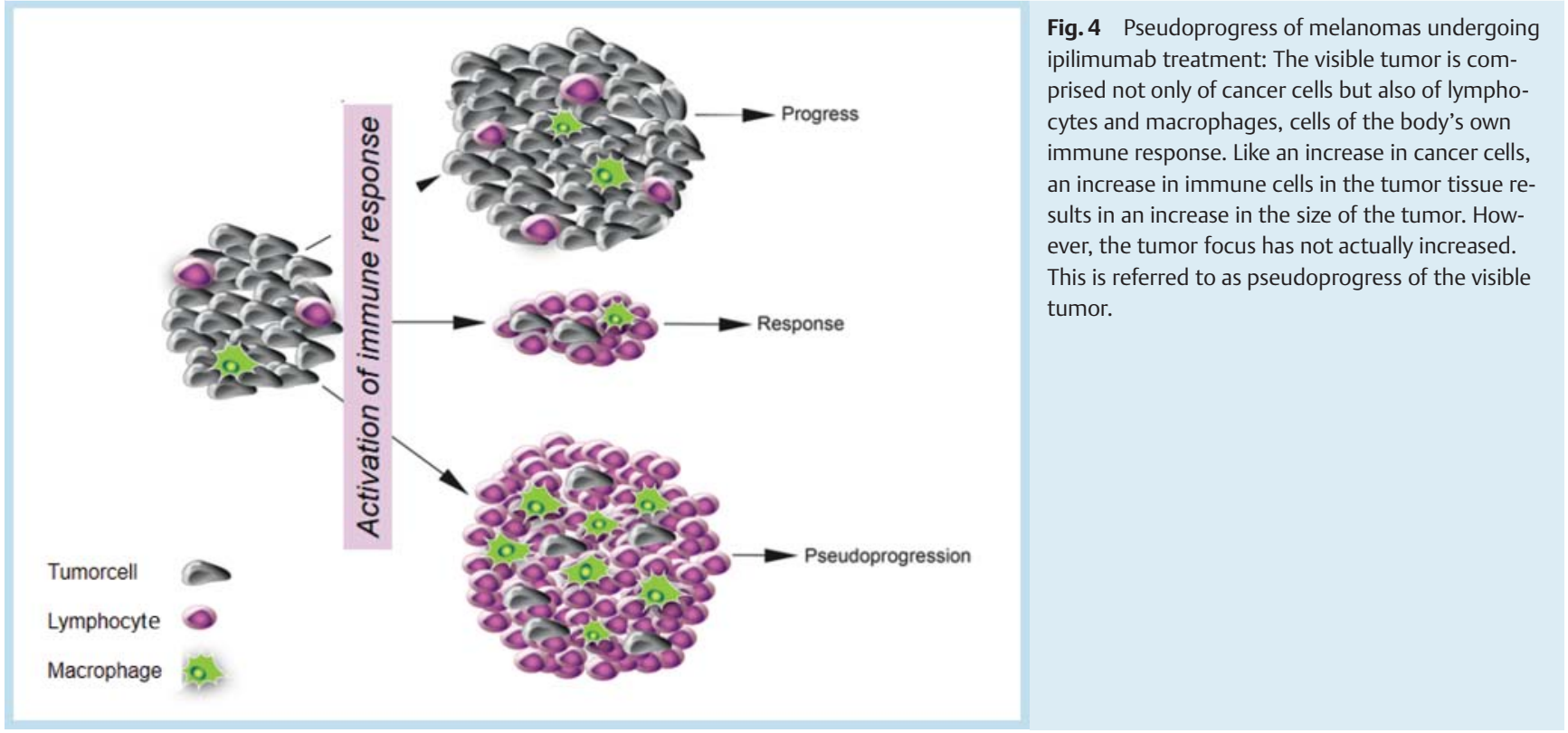

can therefore only be implemented with great difficulty. New methods in which functional information is combined with size information are therefore the focus of many studies [33 - 35]. Apart from FDG-PET/CT, new information regarding tumor activity is primarily expected from diffusion-weighted magnetic resonance imaging (MRI) [36]. Diffusion-weighted MRI is sensitive to the mobility of the large number of water molecules in the human body. Tumors differ from normal tissue in that they have a different cell density and a different content and bonding of hydrogen atoms. Therefore, tumor detection can be simplified and treatment effects can be objectified since free water molecule mobility is indirectly influenced, e.g. by a decrease in cell density.

New developments in computed tomography that make it possible to examine the same body segment with different tube voltages are promising. In contrast to conventional systems, the dual source CT scanner has two X-ray tubes with two detectors that rotate simultaneously around the patient with two different energies and generate two image datasets. Based on the different signal attenuation in the two image datasets, the elementary chemical composi- 

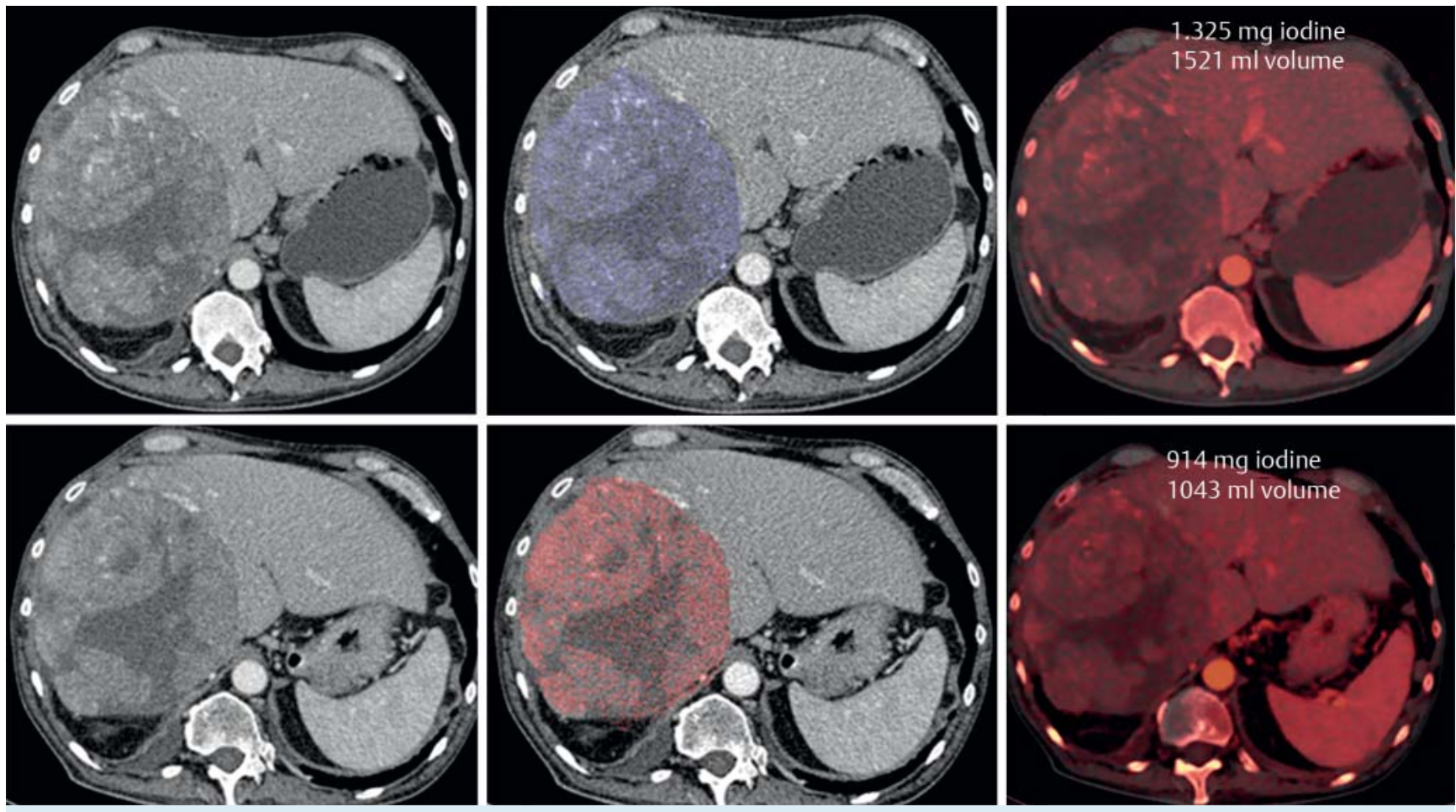

Fig. 5 Dual energy CT of a hepatocellular carcinoma (HCC) treated with sorafenib. In addition to the regular images showing the contrast agent distribution in the tissue and particularly in the tumor (left), a size evalua- tion (middle) can be performed semiautomatically via the quantification of the iodine uptake (right). In this case, the amount of iodine absorbed by the tumor nodule and thus the vital tumor burden decrease during treatment. tion of the scanned tissue can be classified. For better tumor detection, iodine-containing contrast agent is routinely administered intravenously to the patient. It is thus possible to subsequently computationally subtract the iodine content yielding virtually contrast-free images. In addition, image datasets showing the iodine contrast agent distribution in the tissue are available. For tumor followup this concretely means that it is possible to quantify the iodine uptake as a possible tumor vitality parameter in addition to the conventional size determination during the same examination. New generation devices do not require a higher radiation dose than for conventional CT examination [37] ( $\bullet$ Fig. 5).

\section{Unanswered questions \\ $\nabla$}

New radiological methods can unfortunately often not yet be used due to a lack of prospective studies. Radiological studies for evaluating treatment response are also of very low quality or have a low level of evidence compared to oncological studies. Finally, the results must be correlated with concrete parameters, ideally with patient survival (OS).

Treatment monitoring in modern oncology is a task of increasing complexity even after clinical studies. Many questions regarding treatment success have not yet been able to be satisfactorily clarified: Can treatment be ended when a tumor can no longer be morphologically visualized with the usual imaging methods? How is the result "stable disease" to be evaluated in practice and does progression of tumor size necessarily mean that treatment is ineffective?
How is simple slowing of growth differentiated from treatment failure? An answer to these questions helps the treating physician to clarify whether a patient could benefit from additional treatment. Finally it is necessary to determine how to check treatment success in the case of adjuvant therapy, i.e., in the case of no longer macroscopically visible tumors.

\section{Conclusion}

\section{$\nabla$}

The management of patients with solid tumors is about to change radically due to individualized medicine with new targeted therapies. Cancer is increasingly becoming a manageable chronic disease. Therefore, it is important to evaluate the effectiveness of these new treatments early. The evaluation of tumor size according to RECIST $[16,17]$ is still the most frequently used method for monitoring treatment response of solid tumors.

However, the effectiveness of molecular therapies often cannot be determined by tumor size changes. Therefore, evaluation according to RECIST in the case of target therapies should be viewed critically [38] and any additional information regarding tumor biology should be taken into consideration. Targeted therapy requires adapted followup evaluation as already implemented by modern imaging methods for several tumors and presented here. Due to additional method developments, differentiated statements regarding the effectiveness of molecular therapies can be expected. 


\section{Literatur}

1 Nennecke A, Brenner H, Eberle A et al. Überlebenschancen von Krebspatienten in Deutschland: auf dem Weg zu repräsentativen, vergleichbaren Aussagen. Gesundheitswesen 2010; 72: 692 - 699

2 Galbraith SM. MR in oncology drug development. NMR in biomedicine 2006; 19: $681-689$

3 Milano A, Perri F, Ciarmiello A et al. Targeted-therapy and imaging response: a new paradigm for clinical evaluation? Rev Recent Clin Trials 2011; 6: 259-265

4 Romero-Camarero I, Barajas-Diego M, Castellanos-Martin A et al. New models towards assessing anti-cancer therapeutics. Histology and histopathology 2012; 27: 157-170

5 Siegmund-Schultze N. Onkologie: Erfolge bei metastasierten Tumoren. Dtsch Arztebl 2012; 109: 27-28

6 Cousin S, Taieb S, Penel N. A paradigm shift in tumour response evaluation of targeted therapy: the assessment of novel drugs in exploratory clinical trials. Current opinion in oncology 2012; 24: 338-344

7 Choi $\mathrm{H}$. Response evaluation of gastrointestinal stromal tumors. The oncologist 2008; $13: 4-7$

8 Lencioni R, Llovet JM. Modified RECIST (mRECIST) assessment for hepatocellular carcinoma. Seminars in liver disease 2010; 30: 52 -60

9 Wolchok JD, Hoos A, O'Day S et al. Guidelines for the evaluation of immune therapy activity in solid tumors: immune-related response criteria. Clinical cancer research: an official journal of the American Association for Cancer Research 2009; 15: 7412-7420

10 Abou-Alfa GK, Schwartz L, Ricci S et al. Phase II study of sorafenib in patients with advanced hepatocellular carcinoma. J Clin Oncol 2006; 24: $4293-4300$

11 Ganten MK, Weber MA, Ganten TM. Zelluläre Mechanismen der Tumorresponse, klinische Anforderungen. Radiologe 2008; 48: 820 - 831

12 Herzer K, Ganten TM, Schulze-Bergkamen $H$ et al. Transforming growth factor beta can mediate apoptosis via the expression of TRAIL in human hepatoma cells. Hepatology 2005; 42: 183-192

13 Miller $A B$, Hoogstraten B, Staquet $M$ et al. Reporting results of cancer treatment. Cancer 1981; 47: 207-214

14 Wen PY, Macdonald DR, Reardon DA et al. Updated response assessment criteria for high-grade gliomas: response assessment in neurooncology working group. J Clin Oncol 2010; 28: 1963-1972

15 Therasse P, Arbuck SG, Eisenhauer EA et al. New guidelines to evaluate the response to treatment in solid tumors. European Organization for Research and Treatment of Cancer, National Cancer Institute of the United States, National Cancer Institute of Canada. J Natl Cancer Inst 2000; 92: 205-216

16 Eisenhauer EA, Therasse P, Bogaerts J et al. New response evaluation criteria in solid tumours: revised RECIST guideline (version 1.1). Eur J Cancer 2009; 45: 228-247

17 Schwartz LH, Bogaerts J, Ford $R$ et al. Evaluation of lymph nodes with RECIST 1.1. Eur J Cancer 2009; 45: 261 - 267

18 Tsuchida Y, Therasse P. Response evaluation criteria in solid tumors (RECIST): new guidelines. Medical and pediatric oncology 2001; 37: $1-3$

19 Gebauer B, Bohnsack O, Riess H. Radiologische Evaluation des Tumoransprechens in onkologischen Therapiestudien (Tumor Response Evaluation). Fortschr Röntgenstr 2011; 183: 695-703

20 Karul M. RECIST ist einfach-mit RECIST zu arbeiten jedoch nicht! Radiologe 2011; 51: 653
21 Wulff AM, Bolte H, Fischer S et al. Lung, liver and lymph node metastases in follow-up MSCT: comprehensive volumetric assessment of lesion size changes. Fortschr Röntgenstr 2012; 184: 820 -828

22 Levine ZH, Pintar AL, Hagedorn JG et al. Uncertainties in RECIST as a measure of volume for lung nodules and liver tumors. Medical physics 2012; 39: 2628-2637

23 Buchmann I, Ganten TM, Haberkorn U. FDG-PET in der Diagnostik gastrointestinaler Tumoren. Zeitschrift fur Gastroenterologie 2008; 46: $367-375$

24 Wahl RL, Jacene H, Kasamon Y et al. From RECIST to PERCIST: Evolving Considerations for PET response criteria in solid tumors. Journal of nuclear medicine: official publication, Society of Nuclear Medicine 2009; 50: $122 \mathrm{~S}-150 \mathrm{~S}$

25 Ganten MK. Verlaufsbeurteilung des malignen Lymphoms. Radiologe 2012; 52: 330 - 337

26 Cheson BD, Pfistner B, Juweid ME et al. Revised response criteria for malignant lymphoma. J Clin Oncol 2007; 25: 579-586

27 Cheson BD, Horning SJ, Coiffier B et al. Report of an international workshop to standardize response criteria for non-Hodgkin's lymphomas. NCI Sponsored International Working Group. J Clin Oncol 1999; 17: 1244

28 Wessling J, Puesken M, Koch R et al. MSCT follow-up in malignant lymphoma: comparison of manual linear measurements with semi-automated lymph node analysis for therapy response classification. Fortschr Röntgenstr 184: 795-804

29 Rimassa L, Santoro A. Sorafenib therapy in advanced hepatocellular carcinoma: the SHARP trial. Expert review of anticancer therapy 2009; 9: 739-745

30 Kalkmann J, Zeile M, Antoch $\mathrm{G}$ et al. Consensus report on the radiological management of patients with gastrointestinal stromal tumours (GIST): recommendations of the German GIST Imaging Working Group. Cancer Imaging 2012; 12: 126-135

31 Hanahan D, Weinberg RA. The hallmarks of cancer. Cell 2000; 100: 57 70

32 Padhani AR, Koh DM, Collins DJ. Whole-body diffusion-weighted MR imaging in cancer: current status and research directions. Radiology 2011; 261: $700-718$

33 Padhani AR, Miles KA. Multiparametric imaging of tumor response to therapy. Radiology 2010; 256: $348-364$

34 Fueger BJ, Helbich TH, Schernthaner $M$ et al. Stellenwert der multiparametrischen Magnetresonanztomographie beim Prostatakarzinom. Radiologe 2011; 51: 947-954

35 Padhani AR. Integrating multiparametric prostate MRI into clinical practice. Cancer Imaging 2011; 11: S27-S37

$36 \mathrm{LiSP}$, Padhani AR. Tumor response assessments with diffusion and perfusion MRI. Journal of magnetic resonance imaging: JMRI 2012; 35: $745-763$

37 Mangold S, Thomas C, Fenchel M et al. Virtual Nonenhanced Dual-Energy CT Urography with Tin-Filter Technology: Determinants of Detection of Urinary Calculi in the Renal Collecting System. Radiology 2012; 264: 119-125

38 Ratain MJ, Eckhardt SG. Phase II studies of modern drugs directed against new targets: if you are fazed, too, then resist RECIST. J Clin Oncol 2004; 22: $4442-4445$ 